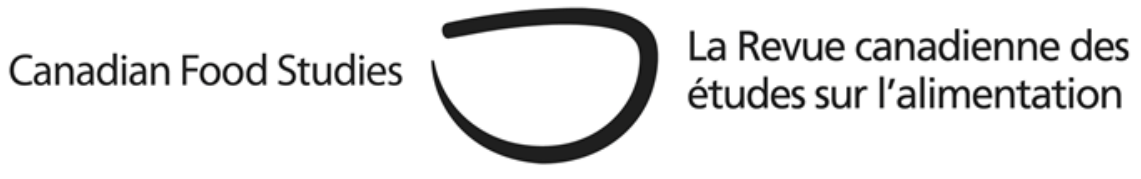

Audio-Visual Work

\title{
Growing food, sharing culture at the Rainbow Community Garden in Winnipeg, Canada
}

\author{
Laura Lucas and Fabiana Li*
}

University of Manitoba

With the COVID-19 pandemic highlighting vulnerabilities in a globalized food system, the ability to grow one's own food seems to be more important than ever. The Rainbow Community Garden enables new immigrant and refugee families in Winnipeg, Manitoba, Canada, to do just that. The project started in 2008 as a community initiative, with 16 newcomer families on one acre of land on the University of Manitoba campus. Since 2008, these numbers have grown, and the garden has expanded to include multiple sites across Winnipeg. While gardeners have faced challenges over the years, including inadequate access to water and economic barriers associated with public transportation to the garden sites, this past summer was their best growing season yet. The Rainbow Garden team has big plans for future improvements to help serve the needs of even more newcomer families. These efforts will be timely and worthwhile, as many immigrants and refugees who already suffer from economic and food insecurity have been disproportionately affected by the impacts of COVID-19.

This photo essay is the outcome of qualitative research conducted by student researcher Laura Lucas under the supervision of anthropologist Dr. Fabiana Li, and with the support of a University of Manitoba Undergraduate Research Award during the summer of 2018. Through interviews with gardeners, a review of the literature on urban agriculture, and participant-observation at the Rainbow Community Garden, this work uncovered compelling stories about a community that has been built around growing food and the shared experiences of newcomers in Winnipeg. The Rainbow Community Garden demonstrates the cultural and multicultural dimensions of food sovereignty and how community gardens can contribute to more sustainable food systems. 


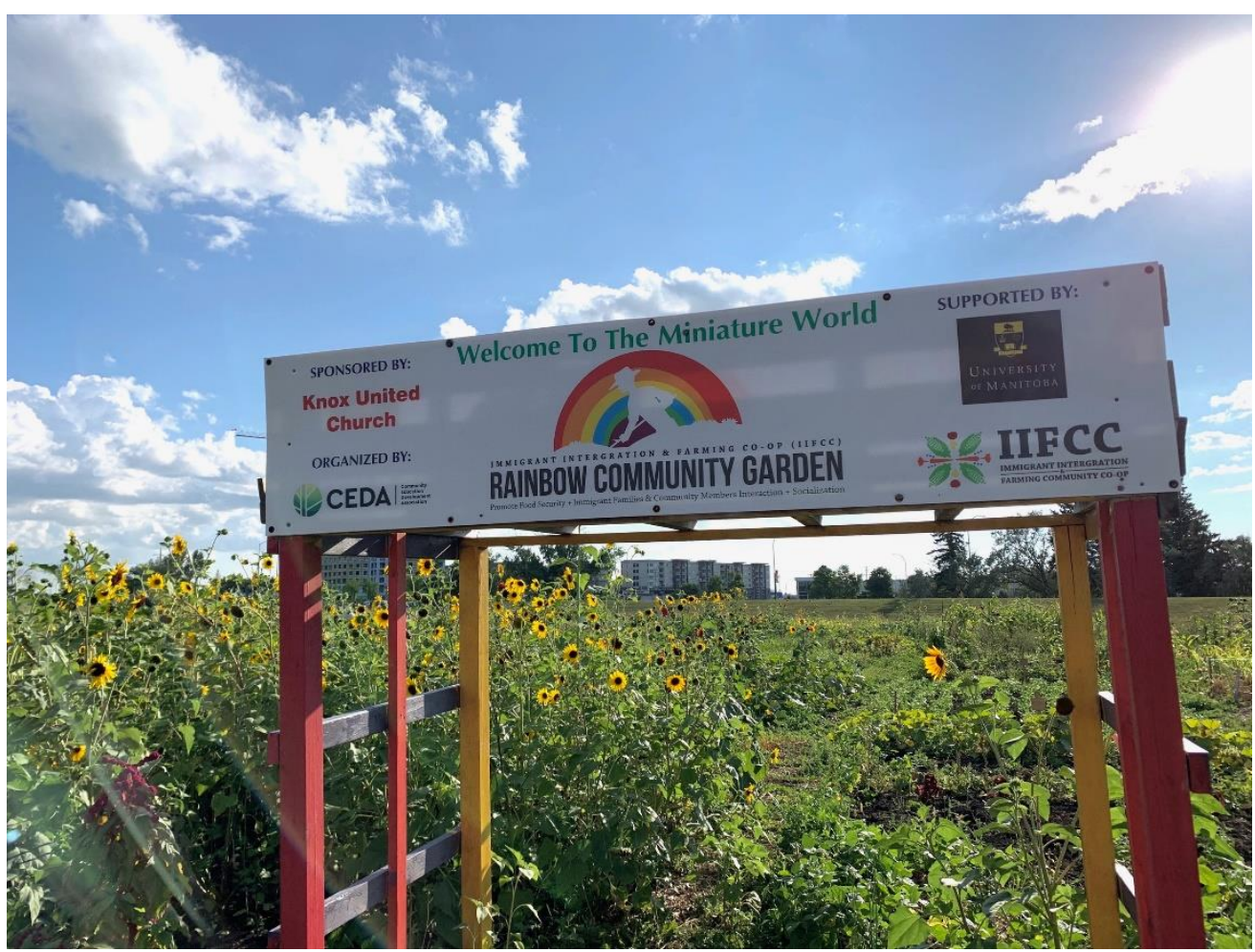

The sign at the Rainbow Garden reads: "Welcome to the Miniature World." It's a reflection of how participants see this small piece of land as encapsulating the cultural diversity of Winnipeg and the wider world. The makeup of the garden participants at any given time is influenced by migration patterns and gardeners currently represent many different parts of the world, from Asia to Africa, and from Latin America to the Middle East. This year, 26 Syrian families joined, bringing the total number of participants in all the garden sites to 324 families. In assigning the plots, priority is given to families and single mothers. The demand exceeds the number of plots available and there is a waiting list of people hoping for a space to open up - or for the garden to expand. 


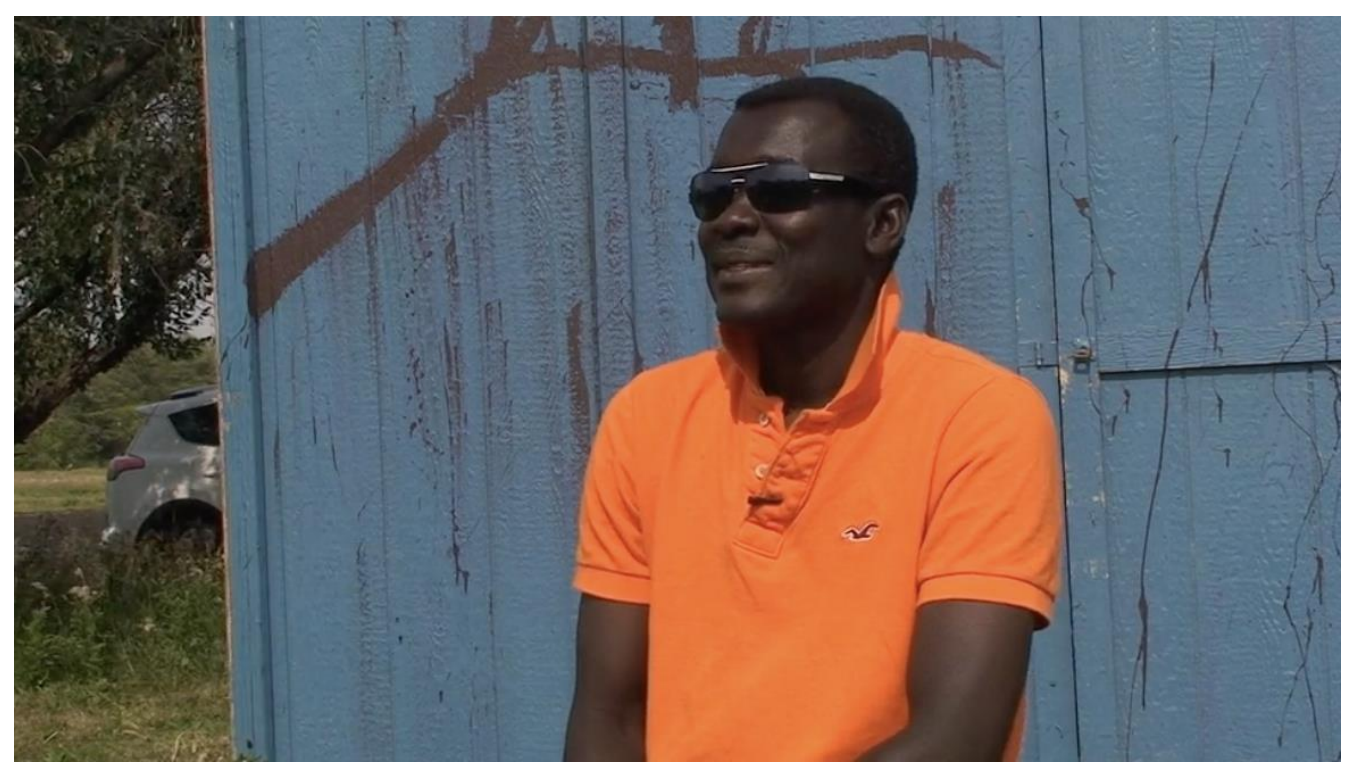

Growing food to feed their families is an obvious benefit of the project, but there are other ways that the garden provides a safe space for families settling into a new city. According to Raymond Ngarboui, the city has been troubled with security issues, gang activity, and violent crimes in neighbourhoods that are home to many immigrant and refugee families: "When they are teenagers and youth, those [immigrant and refugee] kids are the ones who are targeted by gang groups in the downtown area." The families need a place "where they can take them in the summertime, to be together with them, away from the downtown from time to time."

Raymond is one of the key people behind the Rainbow Garden, working behind the scenes to ensure its continuity. Born in Chad, Raymond arrived in Canada as a refugee himself. He has been active in various non-profit organizations in Winnipeg, but his involvement with the Rainbow Garden has been a constant part of his community work. Since he came up with the idea for the project, Raymond has helped forge links with organizations that support the garden (including the University of Manitoba, the Winnipeg Foundation, and the Community Education Development Association), whether through funding and resources or by coordinating volunteer work parties at the garden. More than a place to grow food, the garden is about forging community by bringing together newcomers, volunteers, NGOs, and university students. As one gardener put it, "It seems this garden has a lot of friends, and they are interested to bring their input so that we can do better and do more." 


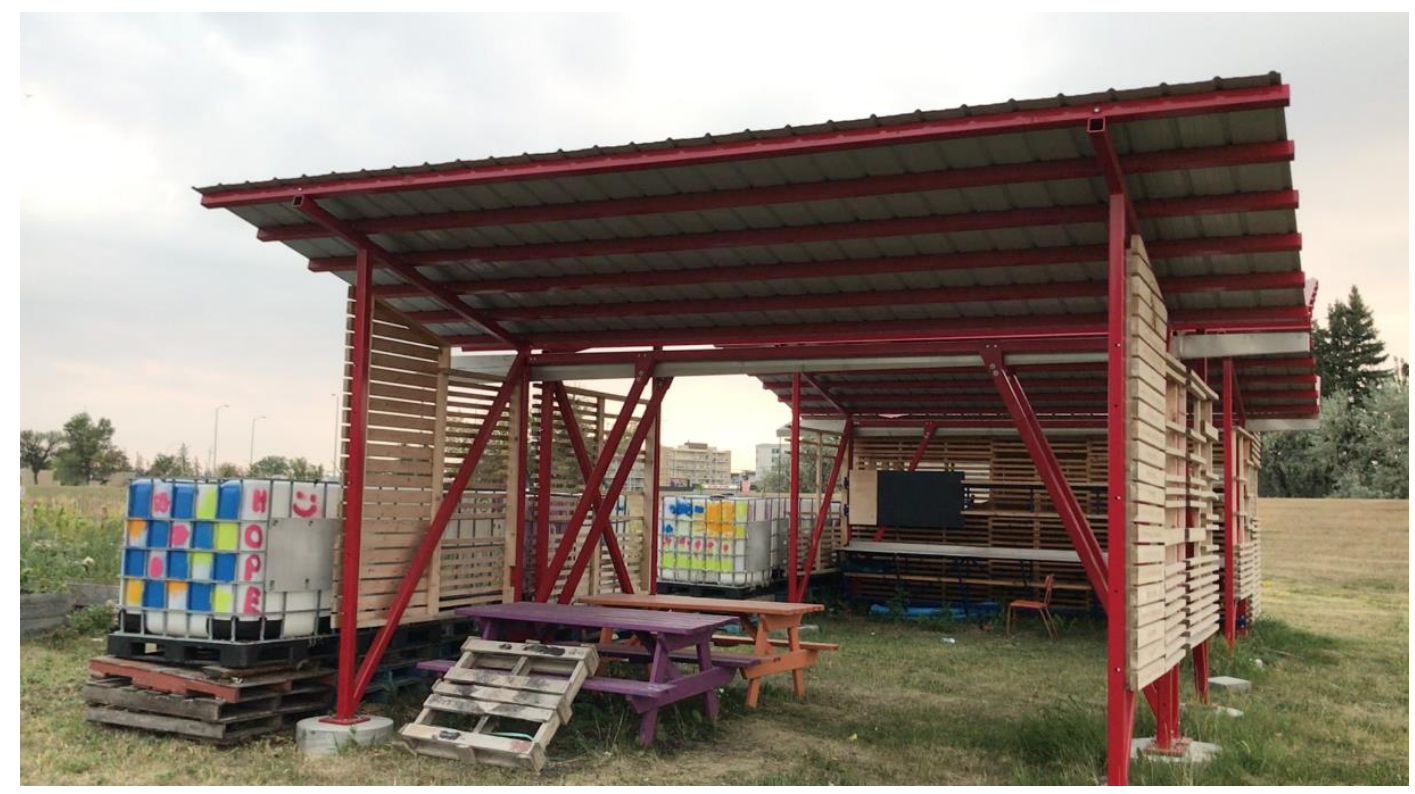

The Rainbow Community Garden works to address some of the unique challenges faced by new immigrants and refugees in Winnipeg. In adjusting to a new way of life in a new country, newcomers face various social, cultural, and economic hurdles. Raymond pointed to mental health as being a significant challenge. When new immigrants remain in their homes and are inactive, it can lead to social isolation, depression, and other mental health issues. The garden helps to combat social isolation by getting gardeners out of their houses and into a community setting. Gardeners can create new relationships with other newcomers while working in their garden plots. There are also events held at the garden, such as potlucks and clean-up days, where newcomers can interact, gain interpersonal skills, and practice English.

Raymond spoke about the garden opening up space for social interaction: "I know many families, family members who, when they start here, it's hard for them even to say hi to others. But in the middle of the growing season, or by the end, they become so open, laughing, interacting with others from different religious backgrounds, sharing food together." Gardeners' physical health can also benefit from participating in the community garden, as it gives them opportunities to get outside and move their bodies, while also going home with some nutritious food to eat. In fostering communal support, strengthening interpersonal relationships among newcomers, and providing healthy food sources, the Rainbow Community Garden provides a strong base for their successful social transition into Canadian society. 


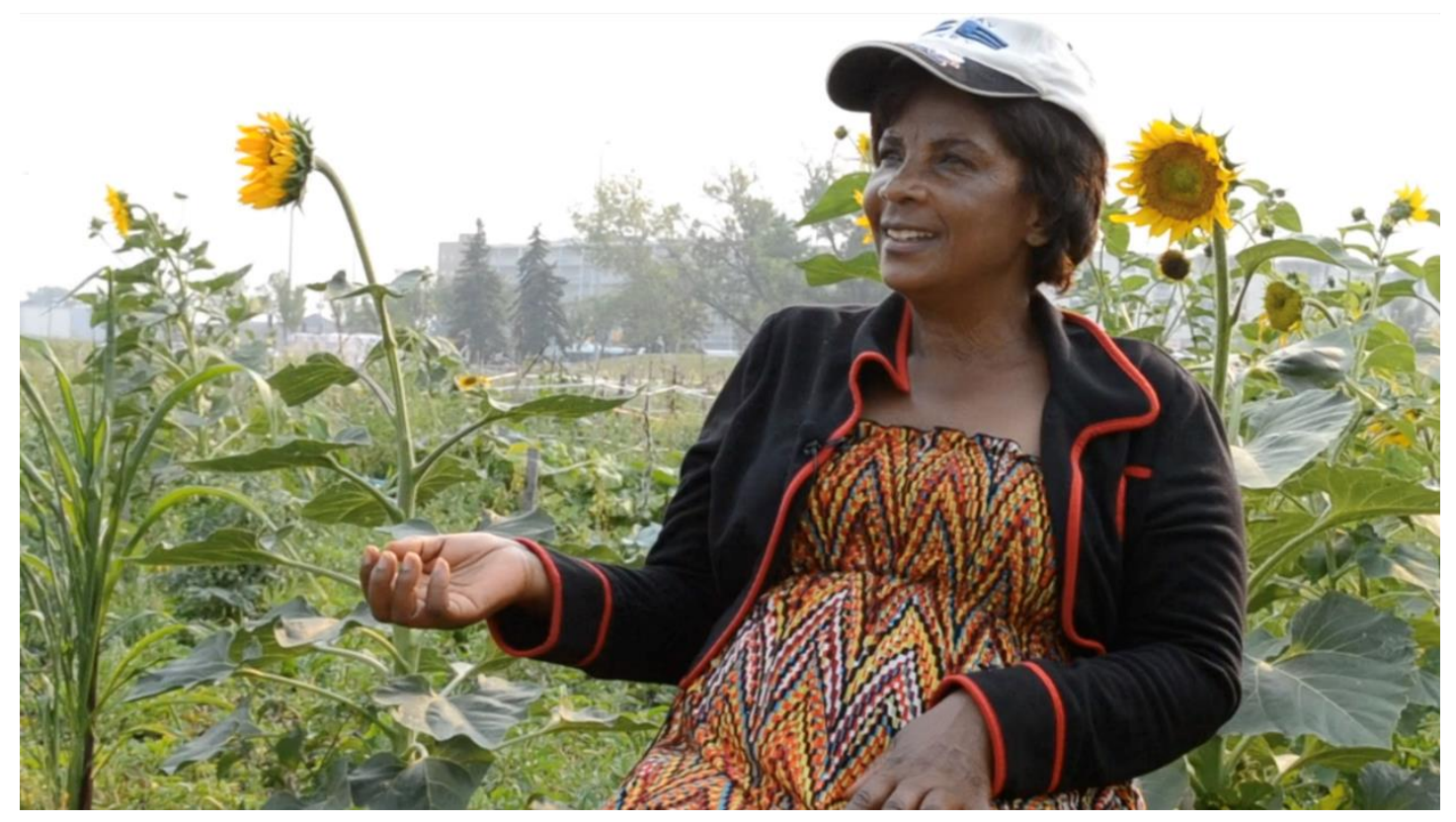

The garden allows participants to celebrate their culture with others, which can help them feel connected to their home country as well as their adopted city. Many Rainbow Garden participants have at least some past experience working on a farm or in a garden before moving to Canada, and for many, gardening was a major part of their lives. Agnes Birime (pictured here) enjoys the stress-free environment of the garden and the memories it brings back from her home country of Burundi. Her father was a farmer and she has been gardening since she was a teenager. Gardeners bring with them gardening techniques and cultural practices from their home countries, even as they must learn to cultivate crops in a place with a different climate and growing season. As gardeners adapt their skills and knowledge to Manitoba's climate and soil conditions, there are opportunities for cross-cultural exchange, as gardeners learn new skills and techniques by seeing how gardeners from other countries do things differently. Through interactions with others at the garden, gardeners also often have the opportunity to try new foods, or learn how to consume a different part of the plant that they are not used to eating, such as the leaves. One gardener expressed a positive outlook on the cross-cultural interaction that takes place at the garden: "We are really chatting because you will see someone maybe from Asia, because they are not used to maybe our type of beans, they will come and say 'Oh what is it?' So we are asking questions of one another to understand what type of plants they have here, and it has created really a good relationship. We meet in the buses, we meet downtown, and we meet during potlucks. And we are happy for that." 


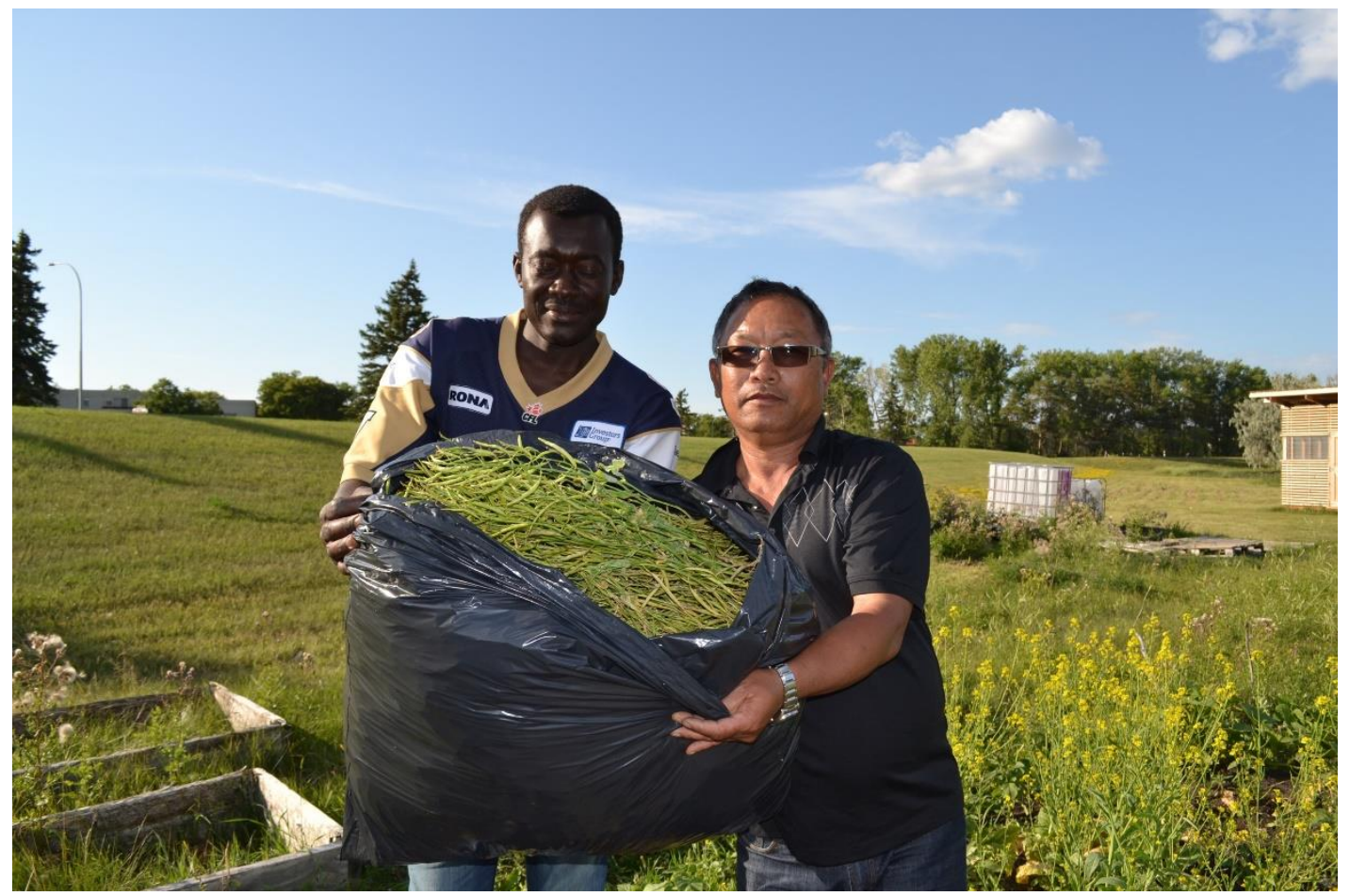

Another way in which the garden benefits newcomers to Winnipeg is by giving them an opportunity to grow culturally appropriate foods. Newcomers often do not have access to some of the ingredients they used to use in their home countries, and when these foods are available, they are often expensive and not fresh. In this photo, Raymond and Mon Bahadur Gurung, a gardener from Nepal, hold a bag of Nepalese mustard seed pods, which were ordered from a seed company in Nepal. This variety of mustard has a distinct flavour from the other varieties of mustard that can be bought in Winnipeg, which often come from other countries such as India. Using the leafy part of the plant, participants at the Rainbow Community Garden are able to make a popular Nepalese dish called gundruk, which is a fermented leafy vegetable dish. With the mustard greens from Nepal, the flavour is closer to what they used to eat in their home country. Often, gardeners will begin to recognize certain vegetables and where they originate. While walking through the many plots at the garden, one participant noted, "When you see mustard leaves like this, that means it's definitely a Nepalese family. And when you see beans, lots of beans and pumpkin, it's Africa." 


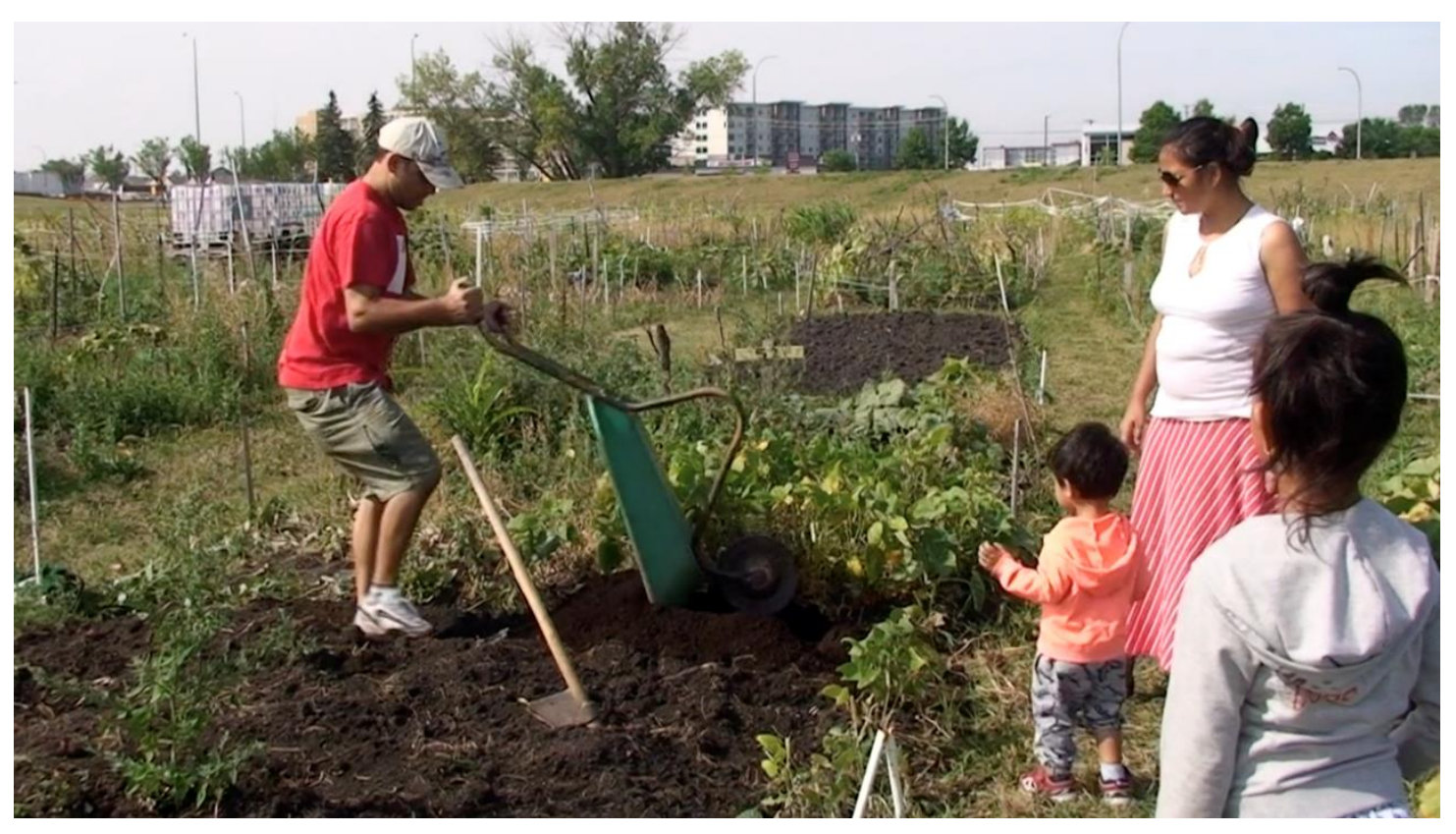

There is also the opportunity for intergenerational learning at the Rainbow Community Garden. In this photo, the Dahal family from Nepal is harvesting potatoes from their garden. The children help their parents to collect the potatoes and carry them away in a wheelbarrow. When parents bring their children with them to the garden, the children learn where food comes from, how it is grown, and the work that is required to grow it. In emphasizing the importance of the garden for his children, one gardener told of a time when he asked his daughter to tell him where their food comes from. He laughed as he shared her answer: "the freezer." Along with general knowledge about food, parents can also pass down cultural knowledge through gardening. For families in which the children were born in Canada, parents can teach them about their cultural heritage through food. This opportunity to transfer knowledge provides a pathway for relationships across cultures and age groups, and is also a chance for families to spend time together while contributing to their own well-being. 


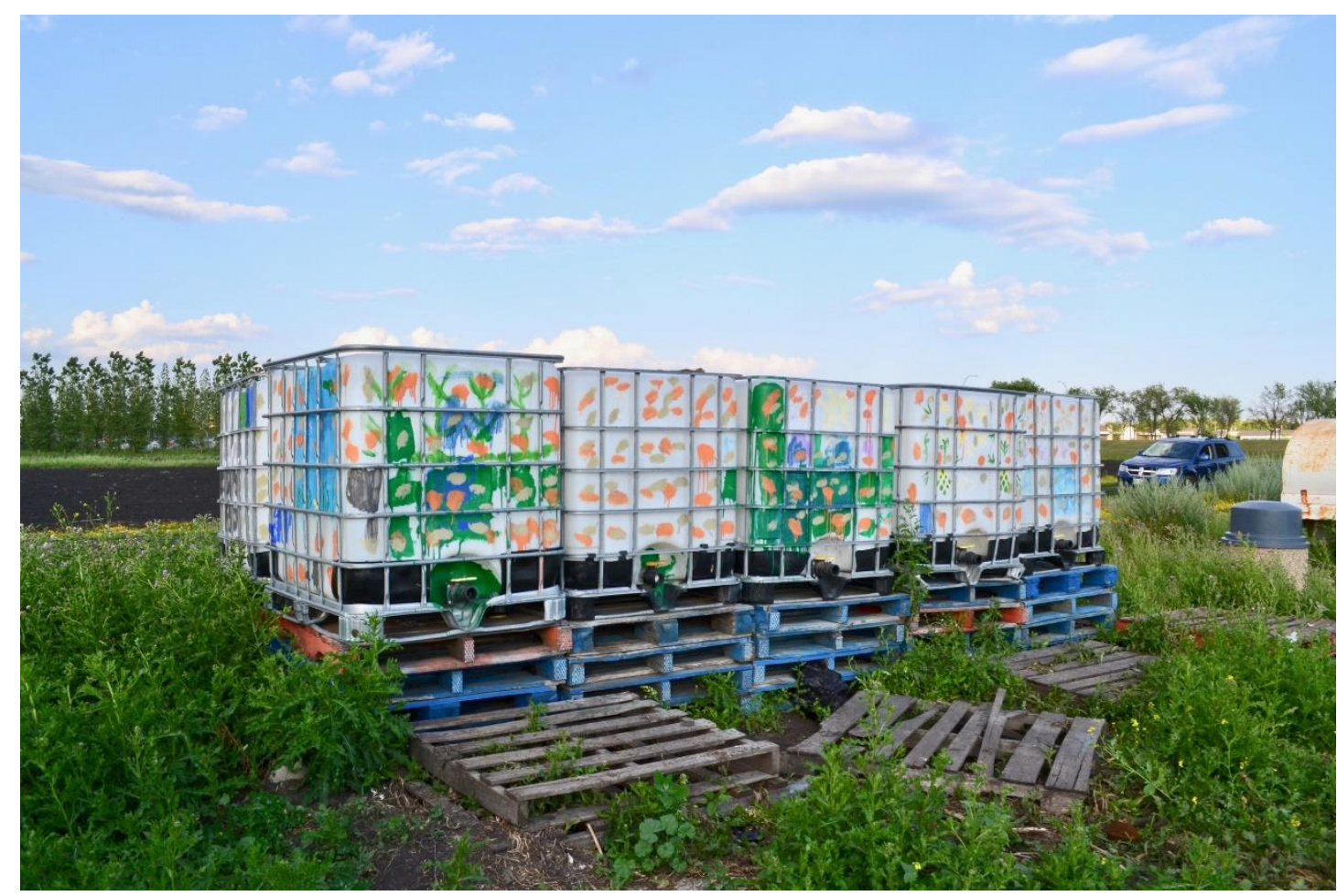

While the Rainbow Community Garden provides a wide range of benefits for gardeners, they also face various challenges. The main challenge for the garden over the past few years has been getting enough water to grow the crops. The water infrastructure at the garden is insufficient to meet the needs of gardeners. People often fill containers with water at home and bring them to the garden, which can be difficult if participants take public transportation. During the last growing season, the water situation improved because the University of Manitoba delivered water to the garden twice a week throughout the season, but it is an ongoing issue, as this was still not enough to provide water for everyone. Raymond says they are looking to improve their access to water through enhanced rainwater collection and water storage, and by continuing to receive water from the university. Another challenge for gardeners has been transportation to and from the garden. Many participants do not own cars, and often do not live within walking distance of the garden. Public transportation is not always accessible due to the high cost of bus tickets. Raymond expressed that this was especially a concern for single mothers who need to bring multiple children to the garden. 


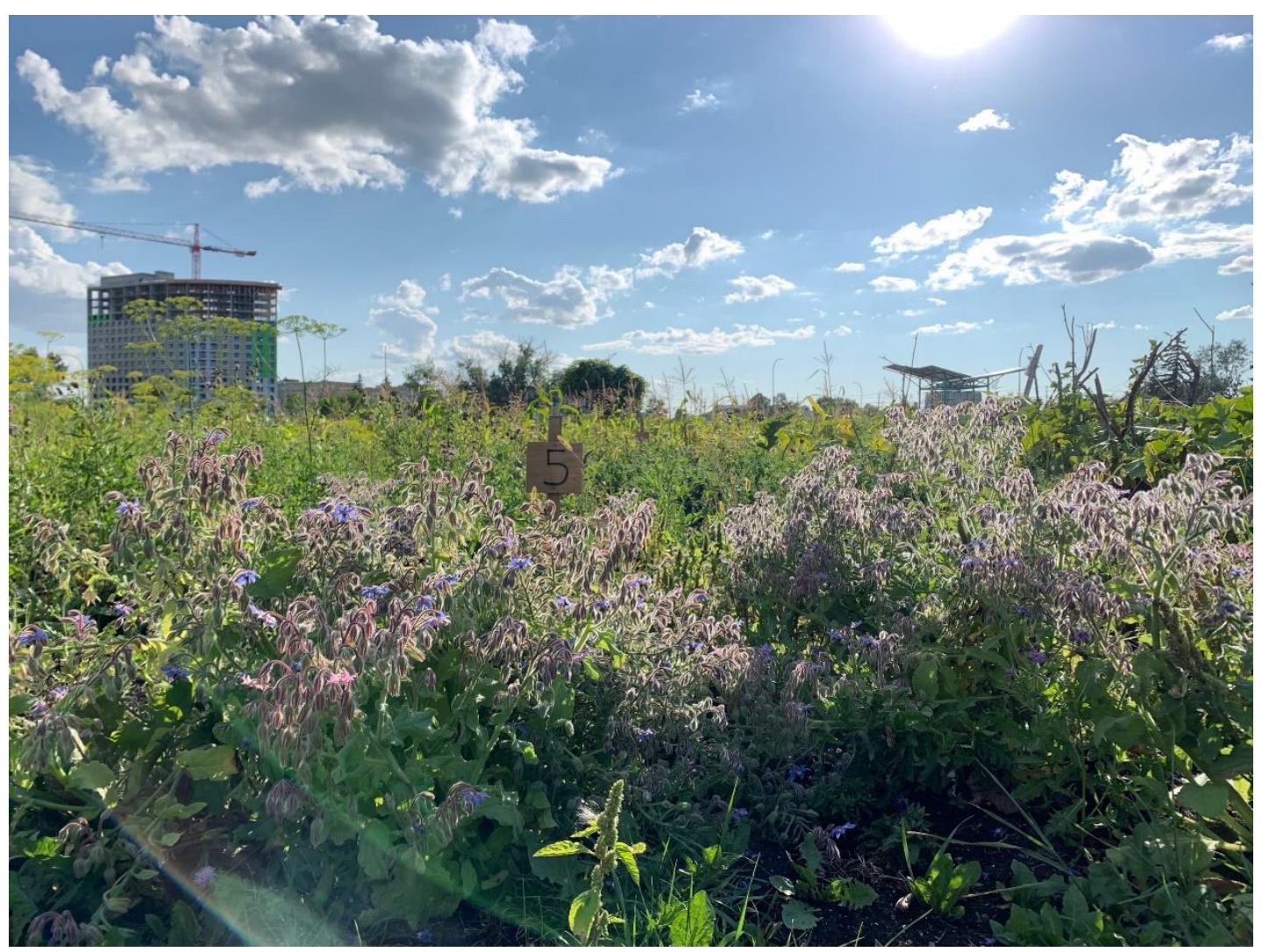

Raymond and the Rainbow Community Garden team have plans to improve the garden in the upcoming growing season. They would like to see enhanced water infrastructure, a seating area for seniors, a playground for children, solar lights to allow families to stay later at the garden, and more raised beds to accommodate more families who are currently on the waiting list. They plan to make these additional raised beds higher, so that they can be more accessible to senior gardeners who are not able to bend down. They also hope to work with the University of Manitoba Architecture Department to implement Phase Two of the infrastructure development, including making improvements to the compost toilet and rainwater collection system. Raymond says the city of Winnipeg could help in terms of improving water infrastructure, delivering compost, and making transportation more affordable for newcomer families who rely on the bus to get to the garden. These improvements will take the Rainbow Community Garden to another level, and will allow them to serve the needs of even more newcomer families in Winnipeg. Even if interactions must take place at an adequate distance due to COVID-19, the Rainbow Community Garden will provide a much-needed spirit of community by bringing people together after an extended period of social distancing. 


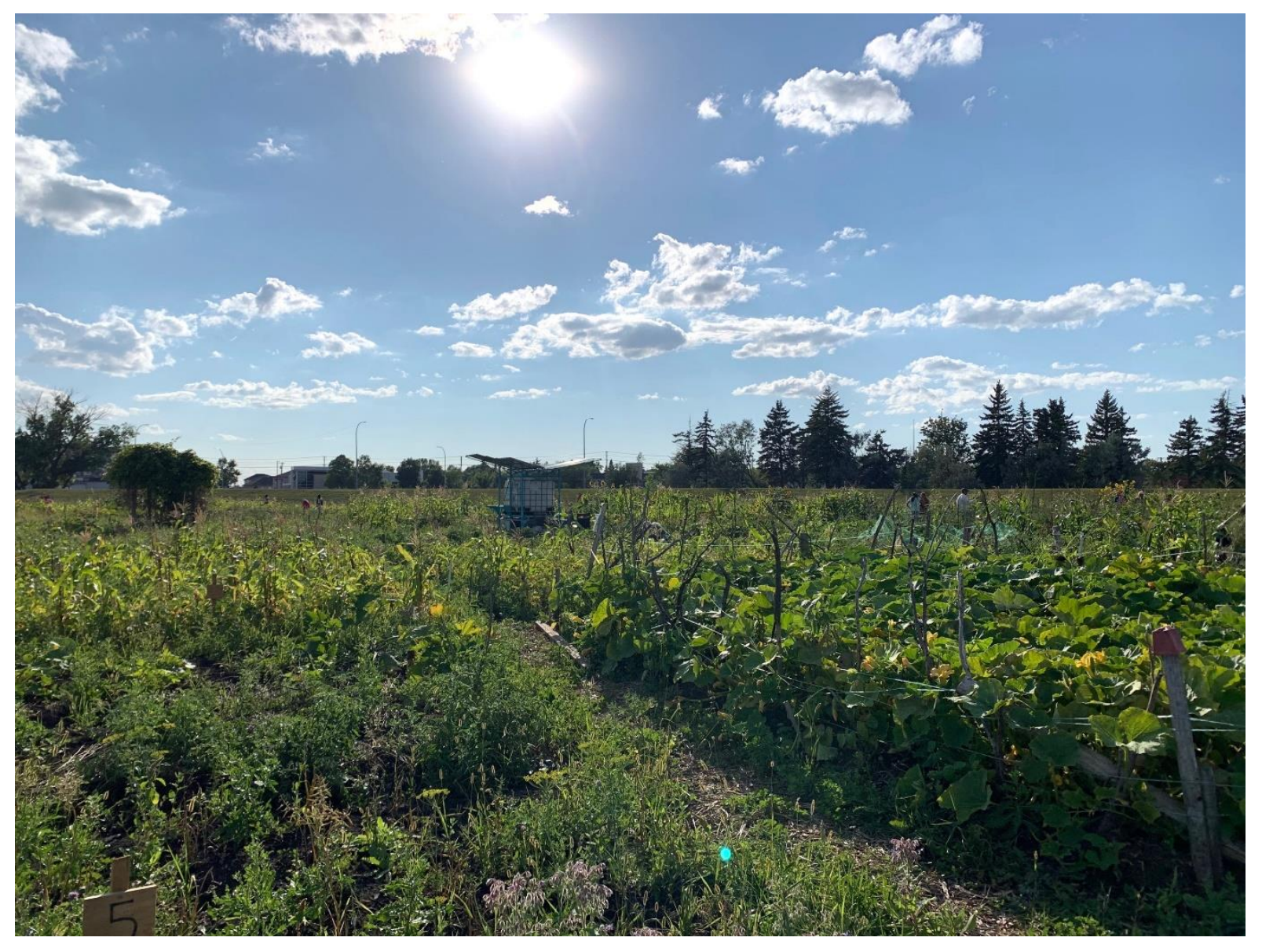

